\title{
Intensive Care Unit Management of the Adult with Congenital Heart Disease
}

\author{
Payton Kendsersky ${ }^{1} \cdot$ Richard A. Krasuski $^{2}$ (B) \\ Published online: 10 September 2020 \\ (C) Springer Science+Business Media, LLC, part of Springer Nature 2020
}

\begin{abstract}
Purpose Adults with congenital heart disease (ACHD) are a rapidly growing population with ever-increasing complexity, and intensive care unit (ICU) management is often necessary. This review summarizes common cardiovascular and noncardiovascular complications in ACHD and provides a framework for ICU care.

Recent Findings Heart failure is the leading cause of hospitalization and mortality in ACHD. Varied anatomy and repairs, as well as differing physiological complications, limit generalized application of management algorithms. Recent studies suggest that earlier mechanical support in advanced cases is feasible and potentially helpful. Cardiac arrhythmias are poorly tolerated and often require immediate attention. Other complications requiring intensive care include infections such as endocarditis and COVID-19, pulmonary hypertension, renal failure, hepatic dysfunction, coagulopathy, and stroke.

Summary Successful ICU care in ACHD requires a multi-disciplinary approach with careful consideration of anatomy, physiology, and associated comorbidities. Few studies have formally examined ICU management in ACHD and further research is necessary.
\end{abstract}

Keywords Adult congenital heart disease $\cdot$ Intensive care unit $\cdot$ Intensive medical care $\cdot$ Advanced heart failure $\cdot$ Extra-cardiac manifestations of ACHD

\section{Introduction}

The number of adults with congenital heart disease (CHD) now significantly exceeds the pediatric congenital heart population [1]. Improvement in diagnosis; medical, transcatheter, and surgical management; and adult congenital heart disease (ACHD) board certification and accreditation for specialized ACHD centers have helped to increase patient survival and improve their quality of life [2]. As the ACHD population ages, their risk for cardiovascular and non-cardiovascular complications

This article is part of the Topical Collection on Congenital Heart Disease

Richard A. Krasuski

richard.krasuski@duke.edu

Payton Kendsersky

payton.kendsersky@duke.edu

1 Department of Medicine, Duke University Medical Center, Durham, NC, USA

2 Division of Cardiology, Duke University Medical Center, DUMC 3010, Durham, NC 27710, USA progressively increases [3•]. Progressive end-organ dysfunction resulting from abnormal physiology also increases their healthcare utilization, particularly when their defects are complex, and repairs are mainly palliative $[4,5 \cdot \bullet]$.

The growing complexity and significant heterogeneity of the ACHD population makes the development of comprehensive guidelines in the acute care setting challenging. Admissions can be precipitated and/or complicated not only by the underlying cardiac condition but also by concomitant medical issues including hepatic dysfunction, pulmonary hypertension, hematologic abnormalities, and neurologic abnormalities. Non-ACHDrelated medical conditions, most recently COVID-19 infection, also require thoughtful and integrated care in the ACHD population. Successful management of the critically ill ACHD patient requires understanding of the individual patient's anatomy and physiology, general knowledge of the commonly associated comorbidities, and congenital heart disease sequelae, as well as familiarity with unique therapeutic modalities. The goal of this review is to provide a simple framework for approaching intensive medical care in the ACHD patient. In general, very few studies have examined intensive care unit (ICU) management of the ACHD patient and further research is desperately needed. 


\section{Advanced Heart Failure and Cardiogenic Shock}

Heart failure (HF) in ACHD can involve either ventricle or a single systemic ventricle as in the case of a Fontan-palliated patient. It can also be diastolic or systolic in nature and is largely lesion dependent and highly variable. HF is the leading cause of morbidity and mortality in ACHD, and HF hospitalizations increased by $83 \%$ from 1998 to 2005 [6]. The 5-year mortality rate following HF hospitalization for ACHD patients is $45 \%$, compared with $8 \%$ for non-HF-related admissions in ACHD patients [2]. Among hospital admissions for heart failure, ACHD patients have substantially higher odds of longer length of stay, incident arrhythmias, and in-hospital mortality [7]. After initial HF hospitalization, the ACHD patient has a 1 -year mortality of $25 \%$, with the highest risk occurring within the first 3 months [8]. It follows that ICUs are increasingly faced with treating the broad physiologic spectrum from advanced HF to cardiogenic shock in ACHD patients. Despite the expanse of evidence-based therapies for HF in acquired cardiac disease, there is little certainty regarding management of ACHD patients, owing to the heterogeneity of anatomy, associated comorbidities, and absence of welldesigned clinical trials in this patient population.

\section{Short-Term Therapies}

Management of advanced HF and cardiogenic shock in the ICU setting generally involves optimizing hemodynamics and eventually bridging to more durable long-term therapies. While intravenous vasoactive drugs can help improve hemodynamics and reverse end-organ dysfunction, several observational studies in non-CHD patients suggest they may worsen clinical outcomes [9]. In ACHD patients, it is important to recognize the significant tradeoff for increasing cardiac contractility with the use of these agents, including an increase in heart rate with the attendant increase in myocardial oxygen demand and impairment of diastolic relaxation, consequences that may be poorly tolerated depending on the underlying cardiac anatomy and physiology. Use of arginine vasopressin may be favored over norepinephrine when treating distributive shock in these patients. At low doses, vasopressin acts through a nitric oxide-dependent mechanism to vasodilate the pulmonary circulation and has demonstrated safety in patients with pulmonary hypertension $(\mathrm{PH})$ [10].

Particularly in patients with $\mathrm{PH}$ and right ventricular (RV) failure, sensitivity to changes in afterload favors the use of particular inodilators, namely phosphodiesterase inhibitors (such as milrinone) and calcium sensitizers (such as levosimendan). Milrinone inhibits the action of phosphodiesterase in the myocyte, leading to increased intracellular cAMP and calcium, acting downstream of the beta-adrenergic receptor. Milrinone, when compared with dobutamine, produces more pulmonary and systemic vasodilation, less tachycardia and myocardial oxygen consumption, and an increased rate of myocardial relaxation [11]. Levosimendan sensitizes cardiac troponin $\mathrm{C}$ for calcium reception in systole [12]. This results in enhanced contractility without concomitantly increasing myocardial oxygen demand or impairing myocardial relaxation. Levosimendan also causes peripheral vascular relaxation reducing cardiac afterload, vasodilates coronary arteries, and may also vasodilate the pulmonary vascular bed [13]. The long half-life (days) of the active metabolite of the drug may also contribute to a more durable hemodynamic effect when compared with other inodilators (dobutamine has a half-life in minutes and milrinone about 2 hours) [14].

Short-term mechanical circulatory support (MCS) can improve outcomes in advanced HF in patients with acquired heart disease and is useful for supporting patients with refractory cardiogenic shock physiology following non-congenital cardiac operations until the cardiopulmonary failure improves. MCS is utilized significantly less in the ACHD population owing to more complicated anatomy, the presence of significant comorbidities, and the overall lack of clinical experience in this patient population [15]. In a study involving the Scientific Registry of Transplant Recipients, only $8.7 \%$ of ACHD patients received some form of MCS, compared with $24.8 \%$ of non-ACHD patients [16].

ACHD patients commonly undergo reoperation and may require MCS for postoperative low cardiac output state that can develop despite attentive medical care. In one small study of postoperative ACHD patients, indications for MCS included left-sided heart failure (32\%), right-sided heart failure (24\%), biventricular heart failure (36\%), persistent arrhythmia (4\%), and significant hypoxemia (4\%) [17]. For short-term mechanical circulatory support, intensivists will generally utilize the intra-aortic balloon pump (IABP), extracorporeal membrane oxygenation (ECMO), or a ventricular assist device (VAD). Despite the lack of benefit seen in the IABPSHOCKII trial, IABPs continue to be utilized in the ICU setting for management of cardiogenic shock [18]. Optimal IABP function is not only dependent on proper balloon positioning but also upon proper inflation timing. The IABP must inflate at the onset of diastole to enhance coronary perfusion and deflate at the onset of aortic valve opening and ventricular emptying to create the negative aortic pressure that reduces ventricular wall stress and afterload. In ACHD patients, unusual anatomy may result in ineffective balloon positioning, and their higher incidence of cardiac arrhythmias can complicate timing of balloon inflation and deflation. In patients with predominant right heart failure, the unloading capabilities of the IABP are limited and, as seen in all patients, it is unable to provide any respiratory support.

Among short-term MCS options, the IABP is less invasive and requires less aggressive anticoagulation than ECMO or VAD placement, which may be preferable in the context of 
the variety of clotting derangements commonly seen in ACHD. In contrast to the IABP, ECMO can provide single or biventricular support (depending on the circuit) as well as respiratory support, making it most attractive for temporary support of biventricular failure, pulmonary dysfunction, or persistent, hemodynamically significant arrhythmias. In addition to the issues with coagulation, providers should also consider the patient's venous drainage, which may be atypical in surgically corrected CHD. Cannula placement can be challenging, and unique problems such as steal from the systemic circulation by Blalock-Taussig shunts or aortopulmonary collaterals can limit full cardiac unloading.

\section{Long-Term Therapies}

In patients who are candidates, cardiac transplantation is the most definitive long-term treatment for end-stage heart failure, and durable MCS devices including the left ventricular assist device (LVAD), biventricular assist device (BiVAD), and total artificial heart (TAH) have demonstrated survival benefit when used to bridge patients to transplantation [19, 20]. VADs (similar to IABP and ECMO) were developed to treat heart failure in patients without congenital cardiac abnormalities. The mechanics of the continuous-flow LVADs, which require an inlet cannula positioned in the apex of the left ventricle, and an outflow graft in the ascending aorta, seemingly depend on predictable anatomy. As a consequence, durable MCS is more often used as a "last resort" in ACHD, as opposed to as an early intervention, which obscures interpretation of its harm or benefit. One study examined the Interagency Registry for Mechanically Assisted Circulatory Support (INTERMACS) to gain insight regarding LVAD, BiVAD, and TAH use in the ACHD population. INTERMACS is a prospective national database of $>16,000$ patients in the USA supported on durable MCS devices. Although the investigators found higher mortality rates overall with MCS for ACHD compared with non-ACHD patients, survival was similar in patients receiving LVADs [21•]. This suggests that increasing the use of LVAD as bridge to transplant in ACHD may lead to improved outcomes. ACHD patients currently spend more time awaiting transplant and have higher mortality rates while doing so [11]. The higher mortality experienced by ACHD patients receiving BiVAD or TAH may suggest a sicker cohort in which the decision for support was delayed too long, and experience with poor outcomes may further bias providers from offering these therapies at more opportune times. The INTERMACS analysis also found increased adverse events with MCS in ACHD, including greater rates of hepatic and renal dysfunction, though these problems can be at least partially attributed to the sequelae of advanced CHD and not simply to a failure of MCS. If the ACHD patient can be supported to surgery, transplant outcomes after MCS are equivalent in ACHD versus non-
ACHD patients, despite increased potential adverse events and the need for repeat sternotomy [22]. Also, the mortality following cardiac transplantation, though higher in the first year, appears lower after 10 years [23]. Figure 1 summarizes the clinical approach to ACHD patients with decompensated heart failure.

\section{Cardiac Arrhythmias}

The number of ACHD emergency department visits related to arrhythmias has been steadily growing and uncontrolled arrhythmias represent the leading cause of death in ACHD [24]. The prevalence and mechanism of arrhythmia varies according to age, underlying anatomic defect, and method of surgical repair. In the ACHD patient hospitalized in the ICU, it is important to consider each of these factors and to evaluate the hemodynamic background that may be contributing. Stenosis of a surgically created/implanted conduit or baffle or worsening valvular stenosis or insufficiency can result in either atrial or ventricular arrhythmia depending on the chambers that are affected. Correction of the hemodynamic aberration itself may resolve the electrical issue [25].

The Fontan population is worth focusing upon (Table 1) given their complex anatomic and physiologic complications. As many as $50 \%$ of post-Fontan patients will develop atrial tachyarrhythmias, often associated with hemodynamic instability [26]. Immediate attention to arrhythmia resolution in Fontan physiology is essential, as arrhythmia is often poorly tolerated and can lead to rapid clinical deterioration. Intraatrial reentrant tachycardia (IART), also referred to as "atypical flutter," is particularly common among surgically repaired ACHD, with an incidence of 16-50\% after Fontan repair, prior Mustard or Senning procedures for d-transposition of the great arteries, or after repair of tetralogy of Fallot [27, 28]. IART generally refers to any macroreentrant atrial tachycardia that does not utilize the cavotricuspid isthmus. It is usually initiated by a premature atrial contraction and requires an intra-atrial conduction delay to be sustained. Conduction from the AV node through the ventricles is not directly impacted unless a functional block develops due to rapid rate. Patients can be asymptomatic, or experience symptoms ranging from palpitations to frank syncope. Persistent and symptomatic IART requires prompt treatment, and long-term sequelae of sustained or recurrent arrhythmia can include the development of cardiomyopathy.

In the acute management of stable IART, vagal maneuvers can be first attempted, followed by intravenous adenosine (first line) or verapamil, both of which have shown efficacy in termination [29]. Long-term pharmacologic therapy for IART suppression is generally not preferred. ACHD patients are younger and will therefore face longer exposures to the toxicities and side effects of antiarrhythmic drugs. Although 


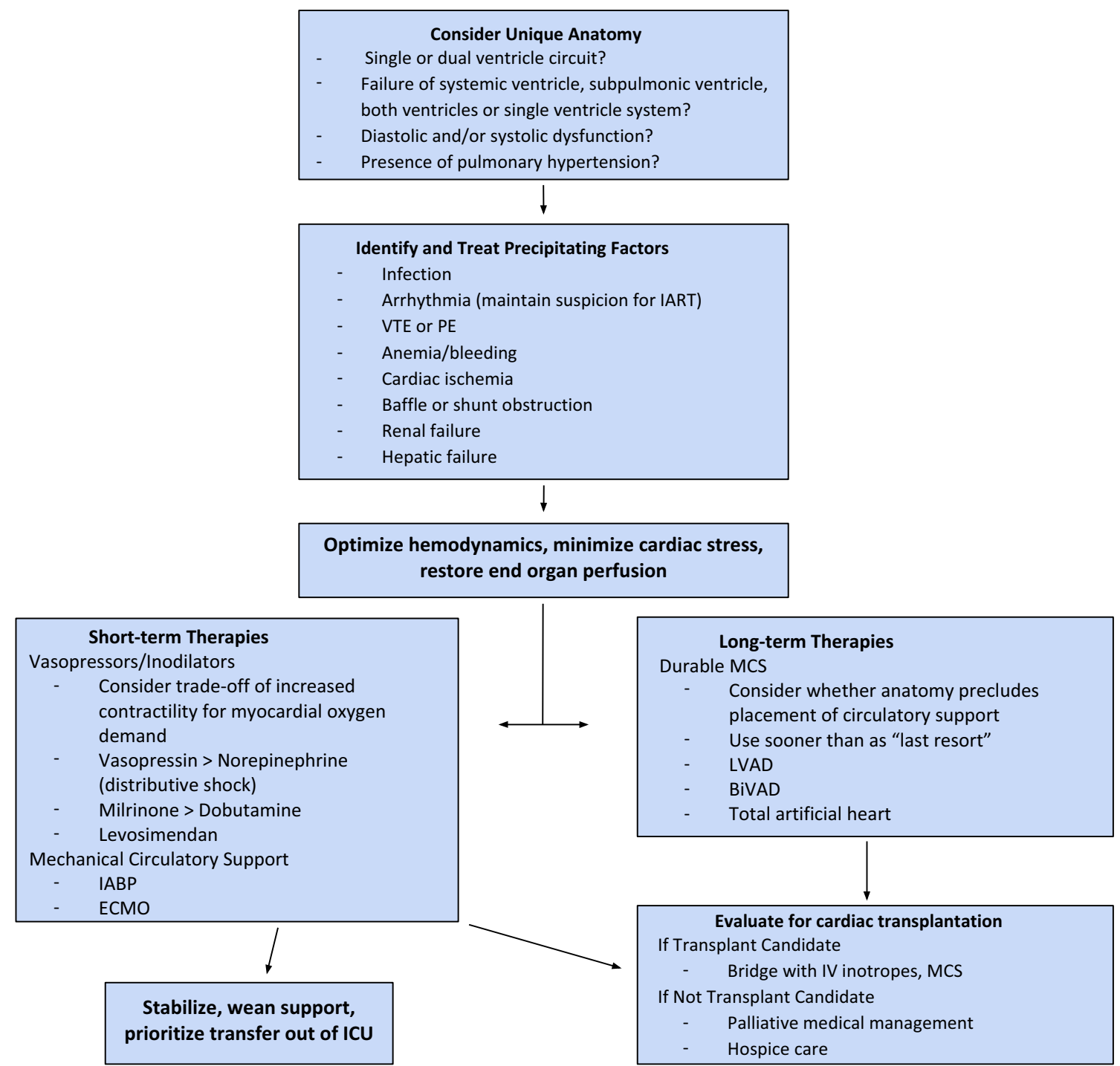

Fig. 1 ICU management of decompensated heart failure in ACHD. BiVAD, biventricular assist device, ECMO, extracorporeal membrane oxygenation; IABP, intra-aortic balloon pump; IV, intravenous; LVAD, left ventricular assist device; MCS, mechanical circulatory support; PE, pulmonary embolism; VTE, venous thromboembolism

A multi-center cohort study evaluated the impact of thromboprophylaxis for atrial arrhythmias in ACHD. $\mathrm{CHADS}_{2}$ and $\mathrm{CHA}_{2} \mathrm{DS}_{2}$-VASc scores were generally low and not predictive of thromboembolic risk. Instead, congenital disease complexity best predicted thromboembolic events. Interestingly, the HAS-BLED score effectively predicted major bleeding with anticoagulation [32]. As a consequence, complex congenital ACHD patients with atrial flutter or fibrillation are generally anticoagulated, regardless of low $\mathrm{CHADS}_{2}$ or $\mathrm{CHA}_{2} \mathrm{DS}_{2}$-VASc scores.

Although when to place a pacemaker in ACHD is beyond the scope of this review, it is important to recognize the important nuances of device implantation in these patients. Certain congenital lesions and their repair techniques predispose to heart block. Sinus node dysfunction is common in atrially repaired (Mustard or Senning) d-transposition, patch- 
Table 1 Summary of Fontan features, complications, and special ICU care considerations

\begin{tabular}{|c|c|c|c|}
\hline $\begin{array}{l}\text { Fontan } \\
\text { anatomic } \\
\text { feature }\end{array}$ & Description & Complications & $\begin{array}{l}\text { Special ICU } \\
\text { considerations }\end{array}$ \\
\hline $\begin{array}{l}\text { Single } \\
\text { ventricle }\end{array}$ & $\begin{array}{l}\text { Anatomic left or } \\
\text { right } \\
\text { ventricle } \\
\text { supports a } \\
\text { univentricular } \\
\text { systemic } \\
\text { circulation } \\
\text { after surgical } \\
\text { repair }\end{array}$ & $\begin{array}{l}\text { - Systolic } \\
\text { dysfunction } \\
\text { - Diastolic } \\
\text { dysfunction }\end{array}$ & $\begin{array}{l}\text { - Anatomy can } \\
\text { complicate } \\
\text { use of } \\
\text { mechanical } \\
\text { assist devices } \\
\text { to help } \\
\text { manage } \\
\text { advanced } \\
\text { heart failure }\end{array}$ \\
\hline $\begin{array}{l}\text { Lack of } \\
\text { subpulmon- } \\
\text { ary ventricle }\end{array}$ & $\begin{array}{l}\text { Circulation } \\
\text { relies on } \\
\text { changes in } \\
\text { intrathoracic } \\
\text { pressure and } \\
\text { augmented } \\
\text { venous return } \\
\text { to draw blood } \\
\text { to the lungs }\end{array}$ & $\begin{array}{l}\text { - Intolerance of } \\
\text { PVR elevation } \\
\text { - Reduced exercise } \\
\text { tolerance } \\
\text { - } \\
\text { Preload-depend- } \\
\text { ent cardiac } \\
\text { output }\end{array}$ & $\begin{array}{l}\text { - Intubation can } \\
\text { result in } \\
\text { increased } \\
\text { PVR and lead } \\
\text { to sudden } \\
\text { drop in } \\
\text { preload and } \\
\text { shock } \\
\text { - Parenchymal } \\
\text { lung } \\
\text { problems and } \\
\text { pleural } \\
\text { effusions are } \\
\text { poorly } \\
\text { tolerated }\end{array}$ \\
\hline $\begin{array}{l}\text { Elevated } \\
\text { central } \\
\text { venous } \\
\text { pressure }\end{array}$ & $\begin{array}{l}\text { High filling } \\
\text { pressures } \\
\text { needed to } \\
\text { drive forward } \\
\text { flow through } \\
\text { the } \\
\text { pulmonary } \\
\text { vasculature in } \\
\text { the absence } \\
\text { of a } \\
\text { subpulmonic } \\
\text { ventricle }\end{array}$ & $\begin{array}{l}\text { - Portal } \\
\text { hypertension } \\
\text { - Hepatic } \\
\text { congestion }\end{array}$ & $\begin{array}{l}\text { - Consider } \\
\text { invasive } \\
\text { hemodynam- } \\
\text { ic monitoring } \\
\text { to maintain } \\
\text { adequate } \\
\text { CVP to } \\
\text { preserve } \\
\text { cardiac } \\
\text { output but } \\
\text { avoid excess } \\
\text { to reduce } \\
\text { hepatic } \\
\text { congestion }\end{array}$ \\
\hline $\begin{array}{l}\text { Hepatic } \\
\quad \text { congestion }\end{array}$ & $\begin{array}{l}\text { Necessary } \\
\text { central } \\
\text { venous } \\
\text { pressure } \\
\text { elevation } \\
\text { results in } \\
\text { passive } \\
\text { venous } \\
\text { congestion }\end{array}$ & $\begin{array}{c}\text { - Liver cirrhosis } \\
\text { - Hepatocellular } \\
\text { carcinoma }\end{array}$ & $\begin{array}{l}\text { - MELD-XI is a } \\
\text { significant } \\
\text { predictor of } \\
\text { major } \\
\text { adverse } \\
\text { cardiac } \\
\text { events } \\
\text { - Patients who } \\
\text { received } \\
\text { blood } \\
\text { transfusion } \\
\text { prior to } 1991 \\
\text { should be } \\
\text { screened for } \\
\text { HCV } \\
\text { infection }\end{array}$ \\
\hline $\begin{array}{l}\text { Atrial surgical } \\
\text { scars and } \\
\text { chamber } \\
\text { dilatation }\end{array}$ & $\begin{array}{l}\text { Atrial wall } \\
\text { incorporation } \\
\text { into Fontan } \\
\text { circuit results }\end{array}$ & $\begin{array}{l}\text { - Predisposition to } \\
\text { sinus node } \\
\text { dysfunction }\end{array}$ & $\begin{array}{r}- \text { IART is a } \\
\text { common } \\
\text { cause of }\end{array}$ \\
\hline
\end{tabular}

Table 1 (continued)

\begin{tabular}{|c|c|c|c|}
\hline $\begin{array}{l}\text { Fontan } \\
\text { anatomic } \\
\text { feature }\end{array}$ & Description & Complications & $\begin{array}{l}\text { Special ICU } \\
\text { considerations }\end{array}$ \\
\hline & $\begin{array}{l}\text { in dilatation; } \\
\text { surgical scars } \\
\text { can result in } \\
\text { conduction } \\
\text { system injury } \\
\text { and } \\
\text { arrhythmic } \\
\text { foci }\end{array}$ & $\begin{array}{l}\text { - Predisposition to } \\
\text { atrial } \\
\text { arrhythmias }\end{array}$ & $\begin{array}{l}\text { hemodynam- } \\
\text { ic } \\
\text { deterioration } \\
\text { - Side effect } \\
\text { profile of } \\
\text { some } \\
\text { antiarrhyth- } \\
\text { mics (e.g., } \\
\text { amiodarone) } \\
\text { are not ideal } \\
\text { long term } \\
\text { - Ablation may } \\
\text { be preferred } \\
\text { as a } \\
\text { long-term } \\
\text { solution }\end{array}$ \\
\hline $\begin{array}{l}\text { Collateral } \\
\text { formation }\end{array}$ & $\begin{array}{l}\text { Development of } \\
\text { veno-venous } \\
\text { collaterals to } \\
\text { help maintain } \\
\text { systemic } \\
\text { preload and } \\
\text { adequate } \\
\text { cardiac } \\
\text { output }\end{array}$ & $\begin{array}{l}\text { - Common cause of } \\
\text { cyanosis } \\
\text { - Potential conduit } \\
\text { for paradoxical } \\
\text { embolism }\end{array}$ & $\begin{array}{l}\text { - Supplemental } \\
\text { oxygen is } \\
\text { unable to } \\
\text { normalize } \\
\text { systemic } \\
\text { saturation } \\
\text { (shunt } \\
\text { physiology) } \\
\text { - Filters on IV } \\
\text { lines to } \\
\text { prevent air } \\
\text { embolism } \\
\text { - Headaches and } \\
\text { mental status } \\
\text { changes } \\
\text { should } \\
\text { prompt } \\
\text { imaging to } \\
\text { assess for } \\
\text { brain abscess }\end{array}$ \\
\hline
\end{tabular}

CVP central venous pressure, $H C V$ hepatitis $\mathrm{C}$ virus, IART intra-atrial reentrant tachycardia, $M E L D-I X$ Model for End-stage Liver Disease eXcluding INR, $P V R$ pulmonary vascular resistance

repaired superior sinus venosus atrial septal defects, and following the Fontan procedure, while 1-transposition and primum atrial septal defect can predispose to atrioventricular nodal block [33]. Access to the ventricle for pacing may be limited (as in Fontan repairs), in which case extra-cardiac lead placement (requiring surgical intervention) may be necessary [34]. In uncorrected shunts with severe pulmonary vascular disease, anticoagulation may be necessary to prevent paradoxical embolism in patients that require temporary wires before permanent pacing can be established. ACHD and its repair can also significantly increase the risk for sudden cardiac death, and it is important to realize that even supraventricular arrhythmias can provoke full cardiac arrest in patients with poor cardiovascular reserve. For further expert, evidence-based 
recommendations on best practice evaluation, diagnosis, and management of arrhythmias in ACHD patients, we direct readers to the 2014 PACES/HRS Expert Consensus Statement on the Recognition and Management of Arrhythmia in ACHD [35].

\section{Infectious Disease Considerations}

\section{Infective Endocarditis}

ACHD is often associated with an increased risk for infective endocarditis (IE), and several contemporary cohort studies have shown significant 30-day in-hospital mortality (7-15\%) for ACHD patients with IE [36, 37]. Early diagnosis and prompt treatment are critical. One study reported an average of 27 days from symptom onset to diagnosis, emphasizing the importance of having a high index of suspicion for IE in these patients [38]. Prior cardiac surgery, presence of prosthetic material, and recent dental work or surgical/interventional cardiac procedures significantly increase IE risk [39]. Surgical intervention will be required in up to half of IE cases in ACHD, related to the development of acute heart failure, severe valvular regurgitation, or recurrent embolic events [40]. Streptococci are the most common causative organisms, while staphylococcal infection is associated with the highest risk of early mortality [41].

\section{Brain Abscess}

Right-to-left shunting results in bypass of the normal phagocytic filtering in the lungs. This increases the risk for brain abscess, with the most common causative organisms being Streptococcus viridans, microaerophilic streptococci, anaerobic streptococci, and haemophilus species. The ICU physician should be vigilant for this problem in any cyanotic congenital heart disease (CCHD) patient with unexplained headaches. Treatment includes antibiotics, though CT-guided stereotactic aspiration or surgical drainage may be necessary $[42,43]$.

\section{COVID-19}

Patients with underlying cardiovascular comorbidities are more likely to suffer complications of COVID-19 infection, such as ARDS, requiring ICU-level care and increasing the risk for mortality [44-46]. As patients with underlying heart disease appear more prone to complications from SARSCoV-2 infection, it follows that ACHD patients should be considered at high risk for severe manifestations of COVID19 [47, 48]. Understanding of viral effects on the cardiovascular system is rapidly evolving. The infection can present with heart failure, myocarditis, and/or arrhythmia, and some centers report Takotsubo-like cardiomyopathy in adults and incomplete Kawasaki-like disease in children [49, 50]. Proposed mechanisms for cardiac involvement include damage to cardiac myocytes due to a hyper-inflammatory response, direct viral entry into cardiac myocytes, or ischemic injury due to severe hypoxia. Both heart failure and myocarditis have been found to be significant contributors to mortality in severe COVID-19 cases. The $25 \%$ incidence of heart failure in COVID-19 may represent myocarditis-induced cardiomyopathy or the unmasking of pre-existing ventricular dysfunction during viral illness [42].

A portal of cell entry for the virus is the angiotensinconverting enzyme (ACE) 2 receptor. Since medications such as ACE inhibitors can upregulate this cell surface protein, there has been concern about this increasing infection risk. A recent meta-analysis, however, has failed to show any epidemiologic impact [51], and position papers from several societies have recommended no alteration to current clinical practice [52]. Thrombosis appears to be increased in COVID-19 and aspirin and/or anticoagulation should also be continued in ACHD patients. Whether anticoagulants should be used to mitigate thrombotic risk in patients not previously taking them is currently unknown. As viral-specific therapies continue to be explored, it is important to consider their impact on the heart, as many antivirals and common antibiotics are associated with QT prolongation and risk of pro-arrhythmia.

\section{Pulmonary Considerations}

Abnormal lung function is common in ACHD for a variety of reasons. Structural abnormalities related to congenital malformation or malposition of pulmonary anatomy, or cardiac chamber enlargement due to pressure or volume overloading lesions, can cause impingement on pulmonary structures during development or later in adulthood. For example, Fontan patients can develop obstruction of the right pulmonary vein by a grossly dilated right atrium (when an atriopulmonary connection was used), or obstruction of the left pulmonary vein by a dilated coronary sinus, both of which can result from volume and pressure overload. Restrictive lung disease is very common, occurring in up to half of ACHD patients, with an even higher prevalence in tetralogy of Fallot and Fontan patients [53]. Furthermore, pulmonary hypertension $(\mathrm{PH})$ has a prevalence ranging from 6 to $28 \%$ in different CHD lesions and can manifest as pulmonary venous hypertension, pulmonary arterial hypertension (PAH), or both, depending on the lesion and prior repair. It is important in the ICU setting to consider direct or indirect hemodynamic assessment of patients to help differentiate the type of pulmonary hypertension and determine the degree of preload dependence. Pulmonary hypertension can be aggravated by pain, hypoxemia, hypercapnia, and acidemia, and hemodynamic stability in ACHD patients, who can have concomitant biventricular failure, is a careful balance between 
pulmonary and systemic vascular resistance. Choosing appropriate management of pulmonary vascular resistance with inhaled nitric oxide; inhaled, parenteral, and oral prostacyclin analogues; and oral phosphodiesterase inhibitors or endothelin antagonists while considering impact on systemic vascular resistance becomes critically important in the decompensated ACHD patient with PH. In the ICU setting, the mainstay of PVR treatment is inhaled nitric oxide (iNO), where route of administration and short half-life contain the pharmacological effects to the pulmonary vasculature [54]. Over time, tachyphylaxis occurs and dosing should be carefully titrated every 24-48 h. Inhaled prostacyclin analogues, treprostinil and iloprost, have longer half-lives compared with iNO and do not require continuous nebulization. Sildenafil, a phosphodiesterase- 5 inhibitor which causes selective vasodilation in pulmonary vasculature, has been used acutely in critically ill patients. It is generally available as an oral preparation and excessive intravenous administration can lead to profound systemic vasodilation. When PAH is refractory to medical therapy, creation of an atrial septostomy or a percutaneous Potts shunt can allow right-to-left shunting to off-load the subpulmonic ventricle. This unfortunately comes at the expense of systemic oxygen saturation and may be less impactful if there is concomitant left heart failure, where elevated left atrial pressure will impede right-to-left shunting.

Intubation should ideally be avoided in patients with $\mathrm{PH}$ or patients with Fontan physiology, as the sudden drop in preload can result in shock [55]. It is also important to ensure adequate volume in these patients if intubation is unavoidable. Mechanical ventilation with low levels of positive endexpiratory pressure (PEEP) can decrease PVR by recruiting more lung, but beyond a certain threshold, higher levels of PEEP will increase PVR and is likely to negatively impact already impaired right ventricular function. With regard to sedation, propofol and midazolam can be safely utilized in ACHD patients with PH as they do not increase PVR. Likewise, for pain management, fentanyl and thoracolumbar epidural analgesia do not impact pulmonary vascular tone. Early extubation should be prioritized and extubating to non-invasive positive pressure ventilation may be beneficial $[56,57]$.

\section{Hematologic Considerations}

ACHD patients are at increased risk for hematologic complications including anemia, polycythemia, thrombocytopenia, and thrombosis, all of which can further complicate management in the ICU setting. Special considerations should be taken for hematological management of CCHD patients.

Evaluation and management of anemia in the critically ill ACHD patient is important, as it is independently associated with increased mortality [58]. Among non-cyanotic ACHD patients, anemia is multifactorial, though some studies have found that iron deficiency may be the most important contributing factor [59]. This can result from acute or chronic blood loss, effects of anticoagulation or antiplatelet drugs, and decreased absorption and increased systemic requirements for iron. Normocytic anemia can occur in up to $40 \%$ of ACHD patients with iron deficiency and should be considered in all cases of anemia where the MCV is less than or equal to $95 \mathrm{fL}$ (sensitivity 97.6\%) [53]. Patients with heart failure are at a higher risk of iron deficiency due to gastrointestinal malabsorption related to right heart congestion, use of aspirin or ACE inhibitors, concomitant renal dysfunction, and associated chronic inflammation. Among ACHD patients, increasing levels of pro-BNP and advanced NYHA functional class are individual risk factors for anemia [60]. Anemia itself can worsen heart failure, further driving this cycle.

Patients with CCHD are more likely to suffer from hemorrhagic complications, assumed in the past to be mostly due to platelet dysfunction, as a large proportion of CCHD patients are thrombocytopenic. Interestingly, the increased red cell production owing to chronic cyanosis also increases bleeding risk. Elevated hematocrit negatively impacts fibrinogen function, which impairs clot formation and clot strength, although platelet function tends to be normal [61]. Likewise, a reduction in hematocrit can improve hemostasis in CHD patients whether or not they are actively bleeding, and platelet counts typically increase dramatically within hours of phlebotomy, especially when the hematocrit is greater than or equal to $65 \%$ [62]. Further investigation in this area is needed; however, monitoring hemostasis with functional analyses of fibrinogen function, as well as treating active bleeding with fibrinogen concentrate, may hold clinical utility in the future.

ACHD patients are also at increased risk of thrombosis, though the mechanisms are less clear. CCHD patients develop secondary erythrocytosis, which may increase thrombotic risk. Should patients become symptomatic due to hyperviscosity, phlebotomy may be beneficial, but only in the context of adequate IV hydration [63]. Ammash and colleagues found an increased incidence of CVA in patients with CCHD; however, it was not associated with increased hemoglobin or hematocrit, but rather with iron deficiency resulting from chronic phlebotomy resulting in increased microcytic and spherocytic erythrocytes [64]. Patients with erythrocytosis appear to benefit from judicious low-dose iron replacement if they are relatively anemic compared with their baseline, with close monitoring to avoid increase in the erythrocytosis response. They should also be adequately fluid repleted to prevent aggravation of hyperviscosity due to dehydration. In the ICU setting, ACHD patients are at high risk of developing thrombosis due to CHD-related coagulopathy, inflammation, and/or platelet activation secondary to extracorporeal circulation support required during open-heart surgery or as a bridge to recovery [65]. One study found $37 \%$ of VTEs in critically 
ill CHD patients were related to central venous catheter (CVC) use and were associated with single-ventricle physiology and number of days of CVC placement [66]. Treatment for VTE in the critically ill ACHD patient can be with unfractionated heparin (goal aPTT 70-100 s) or lowmolecular weight heparin (goal antifactor Xa levels 0.5-1.0), with transition to warfarin long term (goal INR 2-3); greater evidence is needed to be able to recommend use of DOACs for this indication long term. In the presence of life- or limbthreatening thrombosis, lysis should be considered, with very careful monitoring for bleeding consequences including the increased risk of cerebral hemorrhage.

\section{Blood Products}

As mentioned previously, ACHD patients tend to suffer from hematologic complications including anemia, thrombocytopenia, and hemorrhagic and thrombotic events. While it may be necessary to treat patients with blood products in the critical care setting, providers should consider alternative management and exercise caution with transfusion given the risk for allosensitization, which can preclude candidacy for transplantation in the future. Indeed, allosensitization has proven to be a significant barrier to transplantation in ACHD patients [67].

\section{Neurologic Considerations}

The incidence of stroke in the ACHD population is significantly higher than in the age-matched general population, particularly in CCHD. In one study of adult CCHD patients screened with brain MRI, prior stroke was seen in 47\%, with $53 \%$ of these patients having evidence of multiple events [68]. Increased risk was associated with degree of hypoxemia and lesion complexity. Interestingly, polycythemia and hemostatic abnormalities were not found to increase stroke risk. Importantly for inpatient care of CCHD, indwelling venous catheters should be avoided, as these patients are at high risk for iatrogenic stroke from paradoxical air or thrombus embolization.

\section{Hepatic Dysfunction}

In general, hepatic dysfunction in ACHD is a consequence of abnormal hemodynamics, as opposed to primary hepatic abnormalities. Chronic elevation in central venous pressure (CVP) begets portal hypertension, hepatic fibrosis, and cirrhosis. Among ACHD patients, the most well-described liver disease population are patients following Fontan palliation, whose passive return of systemic venous blood directly to the pulmonary arteries results in increased CVP, decreased cardiac output, hypoxia, and hepatic congestion. In the critically ill ACHD patient, examination of hepatic physiology can help define risk. For example, in Fontan patients, thromboembolic events may be associated with liver stiffness [69]. The Model for End-stage Liver Disease eXcluding INR (MELD-XI) score was originally developed to assess cirrhotic patients and has prognostic value for heart failure patients as well. A retrospective cohort study showed MELD-XI remained a significant predictor of MACE in ACHD patients after adjusting for patient characteristics, including sex, functional status, estimated glomerular filtration rate, and cardiac function, while predictive modeling revealed it to be most important variable predicting MACE in this population [70]. Biomarkers may also assist in risk stratification of patients with ACHD and liver complications, with prime candidates including galectin-3 and von Willebrand factor antigen $[71,72]$.

Finally, it is important to note that a large number of current ACHD patients were operated on before 1991 (when widespread screening of donated blood for hepatitis $\mathrm{C}$ began) and almost certainly required blood at the time of surgery. As such, providers should always screen for hepatitis $\mathrm{C}$ when evaluating hepatic dysfunction and cirrhosis in these patients.

\section{Renal Dysfunction}

Renal dysfunction is a common complication of ACHD, effecting nearly half of adults with CHD, and contributing significantly to negative health outcomes. Renal insufficiency is a primary driver of high resource use, accounting for $10 \%$ of ACHD hospitalizations, but up to $33 \%$ of hospital charges [73]. Mild renal insufficiency is associated with twofold increased mortality over 6 years in ACHD patients, and moderate to severe renal insufficiency is associated with a fivefold increase in mortality. Patients with cyanotic CHD in particular, due to both chronic hypoxia and hyperviscosity, are at highest risk for developing chronic kidney disease (CKD). Dimopolous et al. reported mild renal dysfunction in $41 \%$ of their ACHD study population, and moderate to severe renal dysfunction in $9 \%$, with cyanotic patients having a higher rate of moderate or severe renal dysfunction (15.8\%) [74]. Those patients who undergo surgery or a catheter-based intervention are at particular risk for acute kidney injury. Patients who have had multiple previous cardiac surgeries requiring cardiopulmonary bypass more often endure kidney injury postoperatively. Most importantly, a history of AKI in ACHD increases risk of $\mathrm{CKD}$, end-stage renal disease, $\mathrm{CHF}$, and mortality. Patients with CHD can develop type I (acute) and type II (chronic) cardiorenal syndrome, further complicating treatment of CHF. Studies evaluating estimation of glomerular filtration rate in ACHD population are rare. Use of creatinine as a surrogate for renal function in ACHD patients is particularly complicated by heterogeneous non-renal factors including age, muscle mass, and medications. ICU monitoring of 
Table 2 Common diagnoses and considerations by organ system for ICU care of the ACHD patient

\begin{tabular}{|c|c|c|}
\hline $\begin{array}{l}\text { Organ } \\
\text { system }\end{array}$ & Diagnoses & Consideration during ICU monitoring \\
\hline Cardiac & $\begin{array}{l}\text { Advanced heart failure } \\
\text { Dysrhythmia }\end{array}$ & $\begin{array}{l}\text { - Invasive hemodynamic monitoring } \\
\text { - Serial EKG and/or continuous telemetry } \\
\text { - Cardioversion, medications +/- EP study/ablation } \\
\text { - Cardiac imaging } \\
\text { - Biomarkers (troponin, NT-pro-BNP, inflammatory } \\
\text { markers) } \\
\text { - Determine baseline NYHA Functional Class for } \\
\text { decision-making }\end{array}$ \\
\hline Pulmonary & $\begin{array}{l}\text { Pulmonary HTN } \\
\text { Pulmonary embolism } \\
\text { Restrictive lung disease } \\
\text { Impingement of pulmonary } \\
\text { structures }\end{array}$ & $\begin{array}{l}\text { - Avoid intubation if possible-consider non-invasive } \\
\text { respiratory support } \\
\text { - Right heart catheterization }+/- \text { shunt run } \\
\text { - Invasive hemodynamic monitoring } \\
\text { - Chest imaging to better define anatomy } \\
\text { - Temporizing inhaled nitric oxide }\end{array}$ \\
\hline Renal & $\begin{array}{l}\text { Acute kidney injury } \\
\text { Chronic kidney disease } \\
\text { Congenital renal anomalies }\end{array}$ & $\begin{array}{l}\text { - Abdominal ultrasound/CT to exclude obstructive uropathy } \\
\text { - Eliminate nephrotoxins } \\
\text { - Urinary biomarkers (Cr, NGAL, IL-18) } \\
\text { - Evaluate need for CRRT }\end{array}$ \\
\hline Liver & $\begin{array}{l}\text { Portal HTN } \\
\text { Hepatic fibrosis } \\
\text { Cirrhosis } \\
\text { Hepatitis } \\
\text { Hepatocellular carcinoma }\end{array}$ & $\begin{array}{l}\text { - Screen for hepatitis C (if surgeries before 1991) } \\
\text { - Measure CVP and reduce hepatic congestion } \\
\text { - Compute MELD-XI score } \\
\text { - Hepatic biomarkers (galectin-3, vWF antigen, } \\
\text { alpha-fetoprotein) } \\
\text { - Imaging to assess for fibrosis/cirrhosis }\end{array}$ \\
\hline Hematologic & $\begin{array}{l}\text { Anemia } \\
\text { Thrombocytopenia } \\
\text { Coagulopathy } \\
\text { VTE }\end{array}$ & $\begin{array}{l}\text { - Anticoagulant and antiplatelet therapy } \\
\text { - CBC and DIC screen } \\
\text { - Iron studies }\end{array}$ \\
\hline Neurologic & $\begin{array}{l}\text { Cerebrovascular accident } \\
\text { Brain abscess }\end{array}$ & $\begin{array}{l}\text { - Monitor neurologic exam } \\
\text { - Neurological imaging } \\
\text { - High suspicion for brain abscess with longstanding } \\
\text { cyanosis }\end{array}$ \\
\hline
\end{tabular}

$C B C$ complete blood count, $C r$ creatinine, $C R R T$ continuous renal replacement therapy, $C T$ computerized tomography, $C V P$ central venous pressure, $D I C$ disseminated intravascular coagulation, $E K G$ electrocardiogram, $E P$ electrophysiologic, $H T N$ hypertension, $I L-18$ interleukin-18, MELD- $I X$ Model for End-stage Liver Disease eXcluding INR, $N G A L$ neutrophil gelatinase-associated lipocalin, $N Y H A$ New York Heart Association, $v W F$ von Willebrand factor, VTE venous thromboembolism renal function should therefore include alternative serum and urinary biomarkers. Serum cystatin $\mathrm{C}$ has less variability with non-renal variables and can be combined with serum creatinine trends to more accurately estimate GFR [75]. Urinary interleukin 18 (I-18) and neutrophil gelatinase-associated lipocalin (NGAL), can serve as early indicators of postoperative AKI [76].

In critically ill ACHD patients, ultrafiltration or CRRT can be beneficial, but understanding of the underlying pathophysiology of renal impairment is important, particularly in singleventricle physiology. Advanced therapies for end-stage renal disease in ACHD patients can also further increase the risk for infective endocarditis.

\section{Surgery}

One out of seven ACHD surgery hospitalizations results in unplanned readmission [77]. Female gender, lower income status, black race, government-sponsored insurance, renal failure, unscheduled index admission, and category 3 (i.e., moderate complexity) surgical procedures as defined by Risk Adjustment for Congenital Heart Surgery (RACHS-1) are risk factors for subsequent unplanned 30day readmission [78]. The risk for early mortality from surgery is associated with recurrent sternotomies and is improved with increased systemic ventricular ejection fraction [79]. 


\section{Conclusion}

Critically ill ACHD patients require multi-disciplinary care and careful consideration of individual physiology and associated comorbidities (Table 2). It is impossible, with the complexity and variety of ACHD, to give one single approach to caring for the entire patient population. Very few studies have examined ICU management of the ACHD patient and further research is desperately needed. Providers can, however, adopt a conceptual framework to think through the critically ill adult congenital patient, while avoiding the assumption that decompensation is only a result of the cardiac anatomy. An organized approach to caring for these patients includes an understanding of the patient's change from baseline (including cardiac rhythm), the underlying disease (including prior surgeries and repairs), physiology of the current circuit (including single- versus dual ventricle anatomy), and the various organ systems that can be affected (including elevated pressure in the pulmonary vasculature and renal impairment). The goals of ICU care of the ACHD patient should be to identify reversible causes of decompensation, stabilize the patient, and prioritize timely and successful transition out of the unit. By familiarizing oneself with common comorbidities and clinical patterns in the ACHD population, the intensive care provider can optimize medical management and facilitate recovery of this unique and complex patient population.

\section{Compliance with Ethical Standards}

Conflict of Interest Dr. Krasuski serves as a consultant for Actelion Pharmaceuticals. He receives research funding from Actelion and the Adult Congenital Heart Association. He serves as an investigator for Edwards Lifesciences and Corvia Medical. He has received travel grants from Medtronic and CryoLife. Dr. Kendsersky reports no potential conflicts.

Human and Animal Rights and Informed Consent This article does not contain any studies with human or animal subjects performed by any of the authors.

\section{References}

Papers of particular interest, published recently, have been highlighted as:

- Of importance

•. Of major importance

1. Thakkar AN, Chinnadurai P, Lin CH. Adult congenital heart disease. Curr Opin Cardiol. 2017;32(5):467-74. https://doi.org/10. 1097/HCO.0000000000000429.

2. Mizuno A, Niwa K, Ochiai R, Shiraishi I, Sumita Y, Daida H, et al. Impact of facilities accredited by both adult and pediatric cardiology societies on the outcome of patients with adult congenital heart disease. J Cardiol. 2020;75(1):105-9.
3. Agarwal S, Sud K, Menon V. Nationwide hospitalization trends in adult congenital heart disease across 2003-2012. J Am Heart Assoc. 2016;5(1) Trends in hospitalization, outcomes, and resource utilization among patients admitted with ACHD over one decade.

4. Seckeler MD, Thomas ID, Andrews J, Meziab O, Moe T, Heller E, et al. Higher cost of hospitalizations for non-cardiac diagnoses in adults with congenital heart disease. Pediatr Cardiol. 2018;39(3): 437-44.

5.• Lui GK, Saidi A, Bhatt AB, Burchill LJ, Deen JF, Earing MG, et al. Diagnosis and management of noncardiac complications in adults with congenital heart disease: a scientific statement from the American Heart Association. Circulation. 2017;136(20). https:// doi.org/10.1161/cir.0000000000000535 A comprehensive review identifying specific noncardiac comorbidities in ACHD patients. Provides framework for developing key collaborations with clinical services outside cardiology.

6. Verheugt CL, Uiterwaal CSPM, van der Velde ET, Meijboom FJ, Pieper PG, Sieswerda GT, et al. The emerging burden of hospital admissions of adults with congenital heart disease. Heart. 2010;96(11):872-8.

7. Agarwal A, Dudley CW, Nah G, Hayward R, Tseng ZH. Clinical outcomes during admissions for heart failure among adults with congenital heart disease. JAHA. 2019;8(16):e012595.

8. Lal S, Kotchetkova I, Cao J, Jackson D, Cordina R, Celermajer DS. Heart failure admissions and poor subsequent outcomes in adults with congenital heart disease. Eur J Heart Fail. 2018;20(4):812-5. https://doi.org/10.1002/ejhf.1051.

9. Crespo-Leiro MG, Metra M, Lund LH, Milicic D, Costanzo MR, Filippatos G, et al. Advanced heart failure: a position statement of the Heart Failure Association of the European Society of cardiology. Eur J Heart Fail. 2018;20(11):1505-35. https://doi.org/10.1002/ ejhf.1236.

10. Smith AM. The role of vasopressin in cardiorespiratory arrest and pulmonary hypertension. QJM. n.d.;99(3):127-33. https://doi.org/ 10.1093/qjmed/hcl009.

11. Grose R, Strain J, Greenberg M. Systemic and coronary effects of intravenous milrinone and dobutamine in congestive heart failure. $\mathrm{J}$ Crit Care. 1987;2(2):150. https://doi.org/10.1016/0883-9441(87) 90174-2.

12. Egan JR, Clarke AJB, Williams S, Cole AD, Ayer J, Jacobe S, et al. Levosimendan for low cardiac output: a pediatric experience. J Intensive Care Med. 2006;21(3):183-7. https://doi.org/10.1177/ 0885066606287039 .

13. Antoniades C, Tousoulis D, Koumallos N, Marinou K, Stefanadis C. Levosimendan: beyond its simple inotropic effect in heart failure. Pharmacol Ther. 2007;114(2):184-97. https://doi.org/10.1016/ j.pharmthera.2007.01.008.

14. Hansen MS, Andersen A, Nielsen-Kudsk JE. Levosimendan in pulmonary hypertension and right heart failure. Pulm Circ. 2018;8(3):204589401879090.

15. Serfas JD, Patel PA, Krasuski RA. Heart transplantation and mechanical circulatory support in adults with congenital heart disease. Curr Cardiol Rep. 2018;20(10). https://doi.org/10.1007/s11886018-1028-1.

16. Alshawabkeh LI, Hu N, Carter KD, Opotowsky AR, LightMcGroary K, Cavanaugh JE, et al. Wait-list outcomes for adults with congenital heart disease listed for heart transplantation in the U.S. J Am Coll Cardiol. 2016;68(9):908-17. https://doi.org/10. 1016/j.jacc.2016.05.082.

17. Acheampong B, Johnson JN, Stulak JM, Dearani JA, Kushwaha SS, Daly RC, et al. Postcardiotomy ECMO support after high-risk operations in adult congenital heart disease. Congenit Heart Dis. 2016;11(6):751-5. https://doi.org/10.1111/chd.12396.

18. Thiele H, Zeymer U, Thelemann N, Neumann F-J, Hausleiter J, Abdel-Wahab M, et al. Intraaortic balloon pump in cardiogenic 
shock complicating acute myocardial infarction. Circulation. 2019;139(3):395-403. https://doi.org/10.1161/circulationaha.118. 038201.

19. VanderPluym C, Urschel S, Buchholz H. Advanced therapies for congenital heart disease: ventricular assist devices and heart transplantation. Can J Cardiol. 2013;29(7):796-802.

20. Hunt SA, EA, R. The REMATCH trial: long-term use of a left ventricular assist device for end-stage heart failure. J Card Fail. 2002;8(2):59-60. https://doi.org/10.1054/jcaf.2002.32944.

21. Cedars A, VanderPluym CJ, Eghtesady P, Maxwell BG, Gelow $\mathrm{JM}$, Burchill LJ, et al. Outcomes following implantation of mechanical circulatory support in adults with congenital heart disease: an analysis of the Interagency Registry for Mechanically Assisted Circulatory Support (INTERMACS). J Heart Lung Transplant. 2018a;37(1):89-99. https://doi.org/10.1016/j.healun.2017.03.005 An analysis of INTERMACS data demonstrating similar mortality for ACHD patients on LVAD support compared with non-ACHD patients on LVAD support.

22. Maxwell BG, Wong JK, Sheikh AY, Lee PH, Lobato RL. Heart transplantation with or without prior mechanical circulatory support in adults with congenital heart disease. Eur J Cardiothorac Surg. 2014;45(5):842-6. https://doi.org/10.1093/ejcts/ezt498.

23. Bryant R III, Morales D. Overview of adult congenital heart transplants. Ann Cardiothorac Surg. 2018;7(1):143-51. https://doi.org/ 10.21037/acs.2018.01.01

24. Lindsay I, Moore JP. Cardiac arrhythmias in adults with congenital heart disease: scope, specific problems, and management. Curr Treat Options Cardio Med. 2015;17(12):56.

25. Grubb A, Krasuski RA. Don't call the electrician when the problem is the plumbing: resolution of paroxysmal atrial fibrillation with aggressive treatment of pulmonary hypertension. AMSRJ. n.d.;1(2). https://doi.org/10.15422/amsrj.2015.03.021.

26. Deal BJ, Mavroudis C, Backer CL. Arrhythmia management in the Fontan patient. Pediatr Cardiol. 2007;28(6):448-56. https://doi.org/ 10.1007/s00246-007-9005-2.

27. Song MK, Bae EJ, Kwon BS, Kim GB, Noh CI, Choi JY, et al. Intra-atrial reentrant tachycardia in adult patients after Fontan operation. Int J Cardiol. 2015;187:157-63. https://doi.org/10.1016/j. ijcard.2015.03.157.

28. Khairy P, Aboulhosn J, Gurvitz MZ, Opotowsky AR, Mongeon F$\mathrm{P}$, Kay J, et al. Arrhythmia burden in adults with surgically repaired tetralogy of Fallot. Circulation. 2010;122(9):868-75.

29. Garratt C, Linker N, Griffith M, Ward D, Camm AJ. Comparison of adenosine and verapamil for termination of paroxysmal junctional tachycardia. Am J Cardiol. 1989;64(19):1310-6. https://doi.org/10. 1016/0002-9149(89)90573-0.

30. Thorne SA, Barnes I, Cullinan P, Somerville J. Amiodaroneassociated thyroid dysfunction. Circulation. 1999;100(2):149-54. https://doi.org/10.1161/01.cir.100.2.149.

31. Delacretaz E, Ganz LI, Soejima K, Friedman PL, Walsh EP, Triedman JK, et al. Multiple atrial macro-re-entry circuits in adults with repaired congenital heart disease: entrainment mapping combined with three-dimensional electroanatomic mapping. J Am Coll Cardiol. 2001;37(6):1665-76. https://doi.org/10.1016/s07351097(01)01192-5.

32. Khairy P, Aboulhosn J, Broberg CS, Cohen S, Cook S, Dore A, et al. Thromboprophylaxis for atrial arrhythmias in congenital heart disease: a multicenter study. Int J Cardiol. 2016;223:729-35. https://doi.org/10.1016/j.ijcard.2016.08.223.

33. Williams MR, Shepard SM, Boramanand NK, Lamberti JJ, Perry JC. Long-term follow-up shows excellent transmural atrial lead performance in patients with complex congenital heart disease. Circ Arrhythm Electrophysiol. 2014;7(4):652-7. https://doi.org/ 10.1161/circep.113.001321.

34. O'Leary E, Alexander ME, Fynn-Thompson F, Mah D. Transvenous approach to pacemaker lead implantation for sinus node dysfunction after extracardiac lateral tunnel Fontan conduit placement. Heart Rhythm Case Reps. 2016;2(6):495-8. https://doi. org/10.1016/j.hrcr.2016.07.006.

35. Khairy P, Van Hare GF, Balaji S, Berul CI, Cecchin F, Cohen MI, et al. PACES/HRS expert consensus statement on the recognition and management of arrhythmias in adult congenital heart disease: executive summary. Heart Rhythm. 2014;11(10):e81-e101.

36. Moore B, Cao J, Kotchetkova I, Celermajer DS. Incidence, predictors and outcomes of infective endocarditis in a contemporary adult congenital heart disease population. Int J Cardiol. 2017;249:161-5. https://doi.org/10.1016/j.ijcard.2017.08.035.

37. Cahill T, Jewell P, Denne L, Franklin R, Frigiola A, Orchard E, et al. Contemporary epidemiology of infective endocarditis in patients with congenital heart disease: a UK prospective study. Am Heart J. 2019;215:70-7. https://doi.org/10.1016/j.ahj.2019.05.014.

38. Tutarel O, Alonso-Gonzalez R, Montanaro C, Schiff R, Uribarri A, Kempny A, et al. Infective endocarditis in adults with congenital heart disease remains a lethal disease. Heart. 2018;104(2):161-5. https://doi.org/10.1136/heartjnl-2017-311650.

39. Knirsch W, Haas NA, Uhlemann F, Dietz K, Lange PE. Clinical course and complications of infective endocarditis in patients growing up with congenital heart disease. Int J Cardiol. 2005;101(2): 285-91. https://doi.org/10.1016/j.ijcard.2004.03.035.

40. Di Filippo S. Current patterns of infective endocarditis in congenital heart disease. Heart. n.d.;92(10):1490-5. https://doi.org/10.1136/ hrt.2005.085332.

41. Ishiwada N, Niwa K, Tateno S, Yoshinaga M, Terai M, Nakazawa $\mathrm{M}$, et al. Causative organism influences clinical profile and outcome of infective endocarditis in pediatric patients and adults with congenital heart disease. Circ J. 2005;69:1266-70.

42. Fischbein CA, Rosenthal A, Fischer EG, Nadas AS, Welch K. Risk factors of brain abscess in patients with congenital heart disease. Am J Cardiol. 1974;34:97-102.

43. Kagawa M, Takeshita M, Yato S, Kitamura K. Brain abscess in congenital cyanotic heart disease. J Neurosurg. 1983;58:913-7.

44. Ruan, Q., Yang, K., Wang, W., Jiang, L., \& Song, J. (2020). Clinical predictors of mortality due to COVID-19 based on an analysis of data of 150 patients from Wuhan, China. Intensive Care Med.

45. Wu, C., Chen, X., Cai, Y., Xia, J., Zhou, X., Xu, S., Huang, H., et al. (2020). Risk factors associated with acute respiratory distress syndrome and death in patients with coronavirus disease 2019 pneumonia in Wuhan, China. JAMA Intern Med.

46. Zhou F, Yu T, Du R, Fan G, Liu Y, Liu Z, et al. Clinical course and risk factors for mortality of adult inpatients with COVID-19 in Wuhan, China: a retrospective cohort study. Lancet. 2020;395(10229):1054-62.

47. Tan W, Aboulhosn J. The cardiovascular burden of coronavirus disease 2019 (COVID-19) with a focus on congenital heart disease. Int J Cardiol. 2020;309:70-7. https://doi.org/10.1016/j.ijcard.2020. 03.063.

48. Wu Z, McGoogan JM. Characteristics of and important lessons from the coronavirus disease 2019 (COVID-19) outbreak in China. JAMA. 2020;323(13):1239. https://doi.org/10.1001/jama. 2020.2648 .

49. Roca E, Lombardi C, Campana M, Vivaldi O, Bigni B, Bertozzi B, et al. Takotsubo syndrome associated with COVID-19. 2020;7(5): 1. https://doi.org/10.12890/2020 001665.

50. Viner RM, Whittaker E. Kawasaki-like disease: emerging complication during the COVID-19 pandemic. Lancet. 2020;395(10239): 1741-3. https://doi.org/10.1016/s0140-6736(20)31129-6.

51. Usman MS, Siddiqi TJ, Khan MS, Ahmed A, Ali SS, Michos ED, et al. A meta-analysis of the relationship between reninangiotensin-aldosterone system inhibitors and COVID-19. Am J Cardiol. 2020;130:159-61. https://doi.org/10.1016/j.amjcard. 2020.05.038. 
52. American Heart Association. HFSA/ACC/AHA statement addresses concerns re: using RAAS antagonists in COVID-19. European Society of Cardiology. Position statement of the ESC Council on Hypertension on ACE-inhibitors and angiotensin receptor blockers. Published March 13, 2020.

53. Gaeta SA, Ward C, Krasuski RA. Extra-cardiac manifestations of adult congenital heart disease. Trends Cardiovasc Med. 2016;26(7): 627-36. https://doi.org/10.1016/j.tcm.2016.04.004.

54. Krasuski RA, Warner JJ, Wang A, Harrison JK, Tapson VF, Bashore TM. Inhaled nitric oxide selectively dilates pulmonary vasculature in adult patients with pulmonary hypertension, irrespective of etiology. J Am Coll Cardiol. 2000;36(7):2204-11. https://doi.org/10.1016/s0735-1097(00)00994-3.

55. Roche SL, Redington AN. The failing right ventricle in congenital heart disease. Can J Cardiol. 2013;29(7):768-78.

56. Gupta P, Kuperstock JE, Hashmi S, Arnolde V, Gossett JM, Prodhan $\mathrm{P}$, et al. Efficacy and predictors of success of noninvasive ventilation for prevention of extubation failure in critically ill children with heart disease. Pediatr Cardiol. 2013;34(4):964-77.

57. Weismann CG, Yang SF, Bodian C, Hollinger I, Nguyen K, Mittnacht AJC. Early extubation in adults undergoing surgery for congenital heart disease. J Cardiothorac Vasc Anesth. 2012;26(5): 773-6. https://doi.org/10.1053/j.jvca.2012.04.009.

58. Rodríguez-Hernández JL, Rodríguez-González F, MartínezQuintana E. Anemia in adolescents and young adult patients with congenital heart disease. J Pediatr Hematol Oncol. 2018;40(8): $620-4$

59. Dimopoulos K, Diller G-P, Giannakoulas G, Petraco R, Chamaidi A, Karaoli E, et al. Anemia in adults with congenital heart disease relates to adverse outcome. J Am Coll Cardiol. 2009;54(22):2093100. https://doi.org/10.1016/j.jacc.2009.06.050.

60. Eindhoven JA, van den Bosch AE, Ruys TPE, Opić P, Cuypers JAAE, McGhie JS, et al. N-terminal pro-B-type natriuretic peptide and its relationship with cardiac function in adults with congenital heart disease. J Am Coll Cardiol. 2013;62(13):1203-12. https://doi. org/10.1016/j.jacc.2013.07.019.

61. Jensen AS, Johansson PI, Bochsen L, Idorn L, Sørensen KE, Thilén $\mathrm{U}$, et al. Fibrinogen function is impaired in whole blood from patients with cyanotic congenital heart disease. Int $\mathrm{J}$ Cardiol. 2013;167(5):2210-4.

62. Lill MC, Perloff JK, Child JS. Pathogenesis of thrombocytopenia in cyanotic congenital heart disease. Am J Cardiol. 2006;98(2):254-8. https://doi.org/10.1016/j.amjcard.2006.01.083.

63. Rose SS, Shah AA, Hoover DR, Saidi P. Cyanotic congenital heart disease (CCHD) with symptomatic erythrocytosis. J Gen Intern Med. 2007;22(12):1775-7. https://doi.org/10.1007/s11606-0070356-4.

64. Ammash, MD, N. (1996). Cerebrovascular events in adult patients with cyanotic congenital heart disease 28(3), 768-772. https://doi. org/10.1016/s0735-1097(96)00196-9.

65. Silvey M, Brandão LR. Risk factors, prophylaxis, and treatment of venous thromboembolism in congenital heart disease patients. Front Pediatr. 2017;5. https://doi.org/10.3389/fped.2017.00146.

66. Hanson SJ, Punzalan RC, Christensen MA, Ghanayem NS, Kuhn EM, Havens PL. Incidence and risk factors for venous thromboembolism in critically ill children with cardiac disease. Pediatr Cardiol. 2012;33(1):103-8. https://doi.org/10.1007/s00246-011-0098-2.

67. Simpson KE, Cibulka N, Lee CK, Huddleston CH, Canter CE. Failed Fontan heart transplant candidates with preserved vs impaired ventricular ejection: 2 distinct patient populations. J Heart
Lung Transplant. 2012;31(5):545-7. https://doi.org/10.1016/j. healun.2012.02.003.

68. Jensen AS, Idorn L, Thomsen C, von der Recke P, Mortensen J, Sørensen KE, et al. Prevalence of cerebral and pulmonary thrombosis in patients with cyanotic congenital heart disease. Heart. 2015;101(19):1540-6. https://doi.org/10.1136/heartjnl-2015307657.

69. Alsaied T, Possner M, Lubert AM, Trout AT, Gandhi JP, Garr B, et al. Thromboembolic events are independently associated with liver stiffness in patients with Fontan circulation. JCM. 2020;9(2): 418.

70. Konno R, Tatebe S, Sugimura K, Satoh K, Aoki T, Miura M, et al. Prognostic value of the model for end-stage liver disease excluding INR score (MELD-XI) in patients with adult congenital heart disease. PLoS One. 2019;14(11):e0225403.

71. Opotowsky AR, Baraona F, Owumi J, Loukas B, Singh MN, Valente AM, et al. Galectin-3 is elevated and associated with adverse outcomes in patients with single-ventricle Fontan circulation. JAHA. 2016;5(1). https://doi.org/10.1161/jaha.115.002706.

72. Ohuchi, H., Hayama, Y., Miike, H., Suzuki, D., Nakajima, K., Iwasa, T., Konagai, N., et al. (2020). Prognostic value of von Willebrand factor in adult patients with congenital heart disease. Heart, heartjnl-2019-316007.

73. Bhatt $\mathrm{AB}$, Rajabali $\mathrm{A}, \mathrm{He} \mathrm{W}$, Benavidez OJ. High resource use among adult congenital heart surgery admissions in adult hospitals: risk factors and association with death and comorbidities. Congenit Heart Dis. 2015;10(1):13-20.

74. Dimopoulos K, Diller G-P, Koltsida E, Pijuan-Domenech A, Papadopoulou SA, Babu-Narayan SV, et al. Prevalence, predictors, and prognostic value of renal dysfunction in adults with congenital heart disease. Circulation. 2008;117(18):2320-8. https://doi.org/ 10.1161/circulationaha.107.734921.

75. Coll E, Botey A, Alvarez L, Poch E, Quintó L, Saurina A, et al. Serum cystatin $C$ as a new marker for noninvasive estimation of glomerular filtration rate and as a marker for early renal impairment. Am J Kidney Dis. 2000;36(1):29-34. https://doi.org/10.1053/ajkd. 2000.8237.

76. Buelow MW, Dall A, Regner K, Weinberg C, Bartz PJ, Sowinski J, et al. Urinary interleukin-18 and urinary neutrophil gelatinaseassociated lipocalin predict acute kidney injury following pulmonary valve replacement prior to serum creatinine. Congenit Heart Dis. 2012;7(5):441-7. https://doi.org/10.1111/j.1747-0803.2012. 00662.X.

77. Kim YY, He W, MacGillivray TE, Benavidez OJ. Readmissions after adult congenital heart surgery: frequency and risk factors. Congenit Heart Dis. 2017;12(2):159-65. https://doi.org/10.1111/ chd. 12433.

78. Vogt MO, Hörer J, Grünewald S, Otto D, Kaemmerer H, Schreiber $\mathrm{C}$, et al. Independent risk factors for cardiac operations in adults with congenital heart disease: a retrospective study of 543 operations for 500 patients. Pediatr Cardiol. 2012;33(1):75-82.

79. Holst KA, Dearani JA, Burkhart HM, Connolly HM, Warnes CA, $\mathrm{Li} \mathrm{Z}$, et al. Risk factors and early outcomes of multiple reoperations in adults with congenital heart disease. Ann Thorac Surg. 2011;92(1):122-30.

Publisher's Note Springer Nature remains neutral with regard to jurisdictional claims in published maps and institutional affiliations. 